\title{
Making Ends Meet: Microwave-Accelerated Synthesis of Cyclic and Disulfide Rich Proteins Via In Situ Thioesterification and Native Chemical Ligation
}

\author{
Sunithi Gunasekera $\cdot$ Teshome L. Aboye • \\ Walid A. Madian • Hesham R. El-Seedi • \\ Ulf Göransson
}

Accepted: 29 September 2012/Published online: 14 October 2012

(C) The Author(s) 2012. This article is published with open access at Springerlink.com

\begin{abstract}
The development of synthetic methodologies for cyclic peptides is driven by the discovery of cyclic peptide drug scaffolds such as the plant-derived cyclotides, sunflower trypsin inhibitor 1 (SFTI-1) and the development of cyclized conotoxins. Currently, the native chemical ligation reaction between an $\mathrm{N}$-terminal cysteine and C-terminal thioester group remains the most robust method to obtain a head-to-tail cyclized peptide. Peptidyl thioesters are effectively generated by Boc SPPS. However, their generation is challenging using Fmoc SPPS because thioester linkers are not stable to repeated piperidine exposure during deprotection. Herein we describe a Fmoc-based protocol for synthesizing cyclic peptides adapted for microwave assisted solid phase peptide synthesis. The protocol relies on the linker Di-Fmoc-3,4-diaminobenzoic acid, and we demonstrate the use of Gly, Ser, Arg and Ile as C-terminal amino acids (using HBTU and HATU as coupling reagents). Following synthesis, an $\mathrm{N}$-acylurea moiety is generated at the C-terminal of the peptide; the resin bound acylurea peptide is then deprotected and cleaved from the resin. The fully deprotected peptide undergoes thiolysis in aqueous buffer, generating the
\end{abstract}

Electronic supplementary material The online version of this article (doi:10.1007/s10989-012-9331-y) contains supplementary material, which is available to authorized users.

S. Gunasekera - T. L. Aboye - W. A. Madian .

H. R. El-Seedi · U. Göransson ( $\square)$

Division of Pharmacognosy, Department of Medicinal

Chemistry, Biomedical Centre, Uppsala University,

Box 574, 75123 Uppsala, Sweden

e-mail: ulf.goransson@fkog.uu.se

W. A. Madian · H. R. El-Seedi

Department of Chemistry, Faculty of Science, El-Menoufia

University, 32512 Shebin El-Kom, Egypt thioester in situ. Ultimately, the head-to-tail cyclized peptide is obtained via native chemical ligation. Two naturally occurring cyclic peptides, the prototypical Möbius cyclotide kalata B1 and SFTI-1 were synthesized efficiently, avoiding potential branching at the diamino linker, using the optimized protocol. In addition, we demonstrate the possibility to use the approach for the synthesis of long and synthetically challenging linear sequences, by the ligation of two truncated fragments of a 50-residue long plant defensin.

Keywords Fmoc SPPS - Microwave assisted peptide synthesis - Native chemical ligation - Di-Fmoc-3,4diaminobenzoic acid $\cdot$ Cyclotide $\cdot$ kalata B1 $\cdot$ SFTI-1

\section{Introduction}

The discovery of proteins whose ends are linked together to produce a circular topology is an unique event in protein biochemistry. Even though naturally occurring cyclic peptide products, such as cyclosporine, have been known for years, the presence of genetically encoded circular proteins in nature became known only recently. Today it has been established that organisms as diverse as bacteria, plants, fungi and mammals contain the genomic blueprints that are directly translated by nature's ribosomal machinery into circular proteins (Göransson et al. 2012). Currently, the cyclotides (Craik et al. 1999) form the largest family of circular proteins with more than 200 characterized members. These proteins originate from plants and are commonly found within the plant families Rubiaceae and Violaceae.

Cyclotides have captured significant interest because they possess an ultra stable scaffold, the cyclic cystine knot (CCK) motif, derived from the circular backbone and three knotted disulfide bonds. In nature, cyclotides are 
presumably produced by plants to protect themselves against insects (Jennings et al. 2001), although other bioactivities, including anti-tumor (Lindholm et al. 2002; Svangård et al. 2004), anti-bacterial (Gran et al. 2008; Pränting et al. 2010), uterotonic (Gran et al. 2008) and antiHIV (Gustafson et al. 2004), have been reported. A number of 50,000 different cyclotide variants are predicted to be present within the plant family Rubiaceae alone; thus cyclotides represent a natural combinatorial template having their inter-cysteine regions occupied by hypervariable sequences (Wang et al. 2008). Cyclotides are currently a target for bioengineering to take advantage of their plasticity and exceptional stability: bioactive epitopes pertaining to angiogenesis (Chan et al. 2011), anti-angiogenesis (Gunasekera et al. 2008) and protease inhibitory activities (Thongyoo et al. 2008; Thongyoo et al. 2009) have been successfully grafted onto the cyclotide framework.

Another example of a ribosomally synthesized plantderived cyclic peptide is the 14-residue long sunflower trypsin inhibitory 1 (SFTI-1) that was originally discovered from the seeds of Helianthus annus (Luckett et al. 1999). Within its compact structure, SFTI-1 combines a single disulfide bond, a head-to-tail cyclized backbone and a network of internal hydrogen bonds (Korsinczky et al. 2001). Native SFTI-1 has subnanomolar trypsin inhibitory activity, and synthetic analogues of SFTI-1 have been developed into inhibitors of proteases pivotal to the progression of breast and prostate cancers (Long et al. 2001; Boy et al. 2010). Recently, proangiogenic epitopes were successfully grafted onto SFTI-1 (Chan et al. 2011). Lack of complete understanding of biosynthesis and peptide cyclization mechanisms for cyclotides and SFTI-1 has restricted their production by genetic approaches, and currently chemical synthesis remains the most robust approach to produce these molecules. With the rising interest in cyclotides and SFTI-1 as peptide stabilizing templates, it is becoming timely to explore novel approaches for their syntheses. Furthermore, the capacity to chemically synthesize these cyclic peptide templates also provides opportunities to explore the structure-function relationships of individual amino acids via synthetic mutants. Methods of peptide backbone cyclization also have general applicability, with several lines of evidence indicating that cyclization is advantageous in terms of augmenting the stability and bioavailability of therapeutically active peptides such as conotoxins (Clark et al. 2010; Lovelace et al. 2011). The native chemical ligation (NCL) reaction (Dawson et al. 1994) is one of the most popular strategies to join two unprotected peptide segments to each other through a native peptide bond, and can be used for both the synthesis of circular proteins and peptides, and for segmented synthesis of long and difficult peptide sequences (Hackeng et al. 1999; Clark and Craik 2010; Aboye et al.
2011). The ligation requires an $\mathrm{N}$-terminal Cys and a C-terminal $\alpha$-thioester, as outlined in Fig. 1a.

Unprotected C-terminal peptide thioesters, which are the key starting material for NCL, can be directly assembled on resin by Boc SPPS because the thioester is stable to the acidic deprotection treatment used in Boc SPPS. However, Boc SPPS has some drawbacks that make it unsuitable for many laboratories: hazardous HF is used for the final cleavage of the thioester peptide from the resin and the use of the strong acid is incompatible with many posttranslational modifications (Mende and Seitz 2011). On the other hand, thioester peptides are not directly accessible by Fmoc SPPS owing to the nucleophilicity of the Fmoc-deprotecting agent piperidine, although the Fmoc SPPS approach may be considered more user friendly. Several methods have been developed to overcome the problem of thioester instability in Fmoc SPPS; the use of special linkers such as Kenner's safety catch linkers, using non-nucleophilic Fmoc deprotection cocktails or generating/activating the thioester group subsequent to the peptide assembly (Kenner et al. 1971; Clippingdale et al. 2000; Thongyoo et al. 2006; Park et al. 2010).

Recently, Dawson and coworkers described a method for generation of peptide thioesters compatible with Fmoc SPPS, based on a C-terminal $\mathrm{N}$-acylurea peptide moiety (Blanco-Canosa and Dawson 2008). As illustrated in Fig. $1 \mathrm{~b}, O$-aminoanilides are used as stable synthetic intermediates in that method, which in turn are transformed to generate an $\mathrm{N}$-acylbenzimidazolinone ( $N$-acylurea) functionality following peptide assembly. Acidic deprotection gives acylurea peptide, which in turn undergoes thioesterification in neutral aqueous buffer. The C-terminal thioester peptide can then participate in NCL in the presence of the counterpart $\mathrm{N}$-terminal peptide containing the Cys to join the $\mathrm{N}$ - and $\mathrm{C}$-termini.

In the current work, we demonstrate the synthesis of disulfide-rich cyclic peptides with accelerated speed of synthesis and with high yields and purity using microwave assisted Fmoc SPPS. In addition, we demonstrate the use of the approach in a fragment-based synthesis of a larger defensin. The doubly protected Di-Fmoc-3,4-diaminobenzoic acid (illustrated in Fig. 1b) proves to be a useful linker, and Gly, Ser, Arg and Ile were successfully used as starting points for synthesis and subsequent conversion into thioesters.

\section{Materials and Methods}

\section{Materials}

All single Fmoc protected amino acids and Boc-Cys(Trt)-OH were from Iris Biotech (Marktredwitz, Germany) or PepChem (Tübingen, Germany). Tentagel R Ram Rink-type resin $(0.18 \mathrm{mmol} / \mathrm{g})$ and CLEAR amide resin $(0.4 \mathrm{mmol} / \mathrm{g})$ were 
a

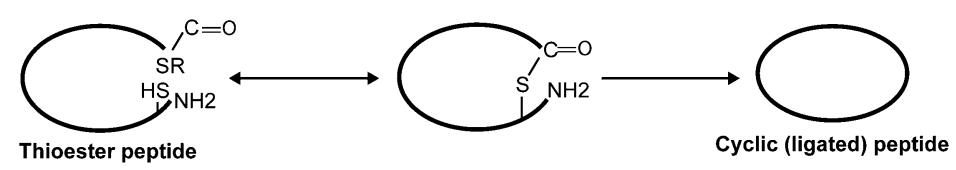

b

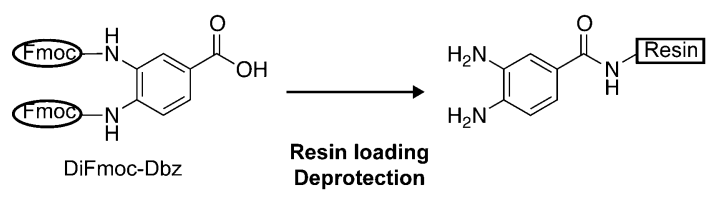

Bmoc-SPPS

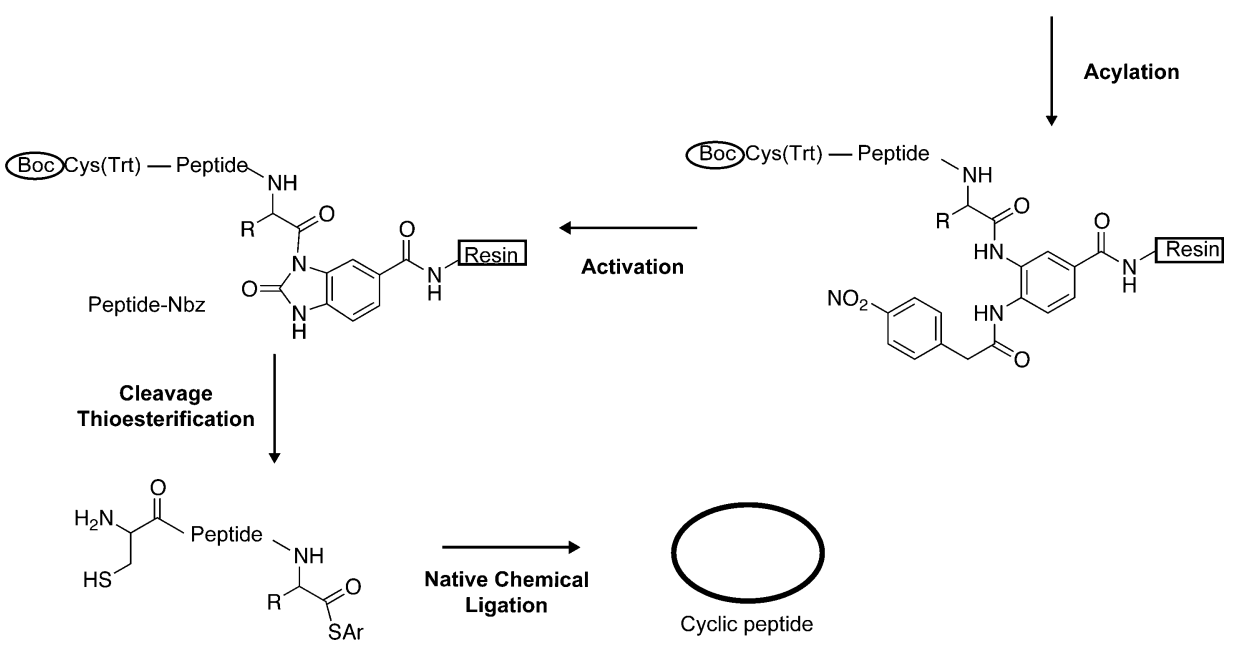

Fig. 1 Schematic illustration of Native Chemical Ligation (NCL) and $\mathrm{N}$-acylurea based Fmoc SPPS synthesis of cyclic peptide synthesis. a The thiolate group of the $\mathrm{N}$-terminal cysteine residue attacks the C-terminal thioester in the unprotected peptide in an aqueous buffer at $\mathrm{pH}$ 7.0. This reversible transthioesterification step is chemo- and region-selective and leads to the formation of a thioester intermediate. That intermediate rearranges by an intramolecular $\mathrm{S}, \mathrm{N}$ acyl shift to form the head-to-tail cyclized peptide. $\mathbf{b}$ In the current work, Di-Fmoc-3,4-diaminobenzoic acid is used as a fully protected linker for the first coupling to the rink amide resin. The linker is then deprotected and peptide chain is elongated along one of the free

amino groups. Following coupling the N-terminal Boc-Cys, the free amino group on the linker is acylated and thus activated, to yield the resin bound $\mathrm{N}$-acyl urea peptide. $\mathrm{N}$-acylurea peptide is then fully deprotected and cleaved from resin by strong cleavage. In situ thioesterification and cyclization according to a then leads to peptide ligation via an amide bond. A topologically circular molecule can be obtained by NCL when the N-terminal cysteine and the C-terminal thioester group are incorporated in the same peptide. Alternatively, the truncated counterpart synthetic peptide fragments can be ligated together to derive such long and difficult to synthesize peptides

from Peptide International (Louisville, KY). Fmoc-Pro NovaSyn TGT $(0.2 \mathrm{mmol} / \mathrm{g})$ and Fmoc-Asp(OtBu)(Dmb)Gly-OH were from Novabiochem/Merck (Darmstadt, Germany). Di-Fmoc-3,4-diaminobenzoic acid was purchased from Anaspec (Fremont, CA). $O$-(7-Azabenzotriazol1-yl)- $N, N, N^{\prime}, N^{\prime}$-tetramethyluronium hexafluorophosphate (HATU), $O$-(Benzotriazol-1-yl)- $N, N, N^{\prime}, N^{\prime}$-tetramethyluronium hexafluorophosphate (HBTU) and Fmoc protected amino acids were from PepChem. $N, N$-Dimethylformamide (DMF) and dichloromethane (DCM) were from Thermo Fisher Scientific (Waltham, MA). HPLC-grade acetonitrile (AcN) and formic acid (FA) were from VWR (West Chester, PA). Diethylether, diisopropylethylamine (DIPEA), guanidine hydrochloride, reduced and oxidized glutathione, piperidine, trifluoroacetic acid (TFA), triisopropylsilane (TIPS), 3,6-dioxa-1,8-octanedithiol (DODT), tris(2-carboxyethyl) phosphine hydrochloride (TCEP), 4-mercaptophenylacetic

acid (MPAA) and 4-nitrophenyl chloroformate were from Sigma-Aldrich (St Louis, MO). PD-10 Sephadex G-25M columns were from GE Healthcare (Uppsala, Sweden).

\section{HPLC and MS}

RP-HPLC was performed on an Äkta Basic (GE Healthcare) with detection at 215, 254 and $280 \mathrm{~nm}$. Preparative HPLC was done on a $250 \times 10$ (i.d.) $\mathrm{mm}$ Phenomenex (Torrance, CA) C18 column (5 $\mu \mathrm{m})$ at a flow rate of $4 \mathrm{ml} /$ min, and analytical HPLC were done on a $150 \times 2$ (i.d.) $\mathrm{mm}$ Phenomenex $\mathrm{C} 18$ column $(3 \mu \mathrm{m})$ at a flow rate of $0.3 \mu \mathrm{l} / \mathrm{min}$. Solvents A (10\%AcN, $0.05 \% \mathrm{TFA}$ in water) and $\mathrm{B}(60 \% \mathrm{AcN}, 0.05 \% \mathrm{TFA}$ in water) were used in a linear gradient from of $0-70 \%$ solvent $\mathrm{B}$ over $70 \mathrm{~min}$ for the preparative HPLC. A linear gradient from 0 to $100 \% \mathrm{~B}$ over $30 \mathrm{~min}$ was used for analytical HPLC. MS and 
LC-MS were done on a LCQ classic (Finnigan/Thermo Electron, San Jose, CA) and a Q-Tof Micro coupled online with a nanoAcquity UPLC (Waters, Milford, MA), respectively. LC-UV-MS was done using an Acquity TUV detector (operated at $215 \mathrm{~nm}$ ) coupled between the UPLC and the Q-Tof Micro. LC-MS was done at a flow rate of $0.3 \mu \mathrm{l} / \mathrm{min}$ on a Acquity UPLC BEH C18 column $(1.7 \mu \mathrm{m}, 150 \times$ $0.075 \mathrm{~mm})$ using solvents $\mathrm{C}(0.1 \% \mathrm{FA}$ in water $)$ and $\mathrm{D}$ $(0.1 \% \mathrm{FA}$ in $\mathrm{AcN})$. A linear gradient from 0 to $60 \%$ solvent $\mathrm{D}$ in solvent $\mathrm{C}$ over $40 \mathrm{~min}$ was used analysis. LC-UV-MS was done using a Phenomenex C18 column $(150 \times 1 \mathrm{~mm}, 5 \mu \mathrm{m})$ eluted at a flow rate of $40 \mu \mathrm{l} / \mathrm{min}$ and a linear gradient from 0 to $60 \%$ solvent $\mathrm{D}$ in solvent $\mathrm{C}$ over $40 \mathrm{~min}$ was used for the analysis.

Peptide Assembly

Kalata B1, SFTI-1 $1_{\text {Arg }}$ and SFT1-1 ${ }_{\text {Ile }}$ were synthesized on a Tentagel R Ram Rink-type resin $(0.19 \mathrm{mmol} / \mathrm{g})$ on $0.1 \mathrm{mmol}$ scale. Defensin fragment 1 was synthesized on a CLEARamide resin using $0.25 \mathrm{mmol}$ scale. Defensin fragment 2 was synthesized on $0.1 \mathrm{mmol}$ scale using Fmoc-Pro-Novasyn TGT preloaded resin. The conditions used in Table 1 were used for the coupling of the Dbz linker and the amino acids to the corresponding resins. Coupling of the $\mathrm{Dbz}$ and the first C-terminal amino acid in kalata B1, SFTI- $1_{\text {Arg }}$, SFTI- $1_{\text {Ile }}$ and defensin peptide 1 were carried out manually. A microwave assisted Fmoc/HBTU SPPS protocol on a Liberty1 microwave peptide synthesizer (CEM Corp., Matthews, NC) was then used for elongation of the full sequences. Defensin fragment 2 was completely assembled in the automated synthesizer. Fmoc-amino acids were Fmoc-Ala-OH, Fmoc$\operatorname{Arg}(\mathrm{Pbf})-\mathrm{OH}$, Fmoc-Asn(Trt)-OH, Fmoc-Asp(OtBu)-OH, Fmoc-Cys(Trt)-OH, Fmoc-Cys(Acm), Fmoc-Gln(Trt)-OH,
Fmoc-Glu(OtBu)-OH, Fmoc-Gly-OH, Fmoc-Ile-OH, FmocLeu-OH, Fmoc-Lys(Boc)-OH, Fmoc-Pro-OH, FmocSer(tBu)-OH, Fmoc-Thr(tBu)-OH, Fmoc-Trp(Boc)-OH, Fmoc-Tyr(tBu)-OH, Fmoc-Val-OH and the dipeptide FmocAsp(OtBu)-(Dmb)Gly-OH. To protect the N-terminus of the peptide during subsequent acylation and to allow simultaneous deprotection, Boc-Cys(Trt)-OH was used in the final coupling step for kalata B1 and SFTI. For defensin fragment 1, a Boc-Arg was coupled at the N-terminal. The following conditions were used in the deprotection and coupling steps in the automated peptide synthesizer (outlined in detail in Table 1). Deprotection was repeated two times: $1 \mathrm{~min}$ $\left(38 \mathrm{~W}, 70^{\circ} \mathrm{C}\right)$ with $20 \%$ piperidine in $\operatorname{DMF}(7 \mathrm{ml})$ followed by of $20 \%$ piperidine in DMF $(7 \mathrm{ml})$ for $3 \mathrm{~min}(63 \mathrm{~W}$, $\left.70{ }^{\circ} \mathrm{C}\right)$. The resin was washed with DMF $(4 \times 7 \mathrm{ml})$. Then $2.5 \mathrm{ml}$ of the reagent mixture, containing amino acid (5 equiv.) HBTU (5 equiv.) and DIPEA (10 equiv.) were transferred to the reaction vessel. All amino acids were coupled for 5 min $\left(32 \mathrm{~W}, 70{ }^{\circ} \mathrm{C}\right)$, except Cys and Arg. Cys was coupled for a total time of $6 \mathrm{~min}(2 \mathrm{~min}$ at room temperature, RT, followed by $4 \mathrm{~min}$ at $50^{\circ} \mathrm{C}$ ) and $\mathrm{Arg}$ was double coupled for $30 \mathrm{~min}$ ( $25 \mathrm{~min}$ at RT followed by $5 \mathrm{~min}$ of $75^{\circ} \mathrm{C}$ ). After completed synthesis, resins were washed $(3 \times 7 \mathrm{ml}, \mathrm{DMF} ; 4 \times 10 \mathrm{ml} \mathrm{DCM})$ and dried under $\mathrm{N}_{2}$.

\section{Cleavage from Resin}

Following synthesis, a sample of the resin (50 mg) was taken out and cleaved with TFA/TIPS/water (95.5:0.25:0.25, 2-3 h, RT). The cleaved peptide was filtered from resin, dried down to $0.5 \mathrm{ml}$ with $\mathrm{N}_{2}$ and precipitated by the addition of cold diethylether. The precipitate was collected by centrifugation, redissolved in $50 \% \mathrm{AcN} / 0.05 \% \mathrm{TFA}$ and freeze dried.

Table 1 Synthetic conditions used during peptide elongation

\begin{tabular}{|c|c|c|}
\hline Step & Reagents & Target temperature ${ }^{\mathrm{a}}$ and duration \\
\hline Deprotection of resin & $20 \%$ piperidine, $7 \mathrm{ml}$ & $\mathrm{RT}, 20 \min \times 1$ \\
\hline Coupling of Dbz & Dbz (1 eqiv.), HBTU (2 eqiv.) DIPEA (3 eqiv.) & $\mathrm{RT}, 30 \min \times 2$ \\
\hline Deprotection of Dbz & $20 \%$ piperidine, $7 \mathrm{ml}$ & $\mathrm{RT}, 20 \min \times 2$ \\
\hline Initial deprotection of aa & $20 \%$ piperidine, $7 \mathrm{ml}$ & $70^{\circ} \mathrm{C}, 1 \mathrm{~min}$ \\
\hline Deprotection of aa & $20 \%$ piperidine, $7 \mathrm{ml}$ & $70{ }^{\circ} \mathrm{C}, 3 \mathrm{~min}$ \\
\hline \multicolumn{3}{|l|}{ Coupling of first aa } \\
\hline Gly & aa (2 eqiv.), HBTU (2 eqiv.), DIPEA (3 eqiv.) & $\mathrm{RT}, 30 \mathrm{~min}$ \\
\hline Ser & aa (4 eqiv.), HBTU (4 eqiv.), DIPEA (6 eqiv.) & $\mathrm{RT}, 30 \min (\times 2)$ \\
\hline Ile/Arg & aa (6 eqiv.), HATU (6 eqiv.), DIPEA (9 eqiv.) & $\mathrm{RT}, 1 \mathrm{~h} \times 2$ \\
\hline \multicolumn{3}{|l|}{ Coupling of other aa } \\
\hline aa other than Cys or Arg & aa (5 eqiv.), HBTU (5 eqiv.), DIPEA (10 eqiv.) & $70^{\circ} \mathrm{C}, 5 \mathrm{~min}$ \\
\hline Cys & aa (5 eqiv.), HBTU (5 eqiv.), DIPEA (10 eqiv.) & $\mathrm{RT}, 2 \mathrm{~min}$ and $50^{\circ} \mathrm{C}, 5 \mathrm{~min}$ \\
\hline Arg & aa (5 eqiv.), HBTU (5 eqiv.), DIPEA (10 eqiv.) & $\mathrm{RT}, 25 \mathrm{~min}$ and $70^{\circ} \mathrm{C}, 5 \mathrm{~min}$ \\
\hline
\end{tabular}

aa amino acid

${ }^{\text {a }} \mathrm{RT}$ indicates coupling at room temperature; $\delta \mathrm{T}=5 \mathrm{~min}$ under microwave heating 
Conversion of Dbz-Peptides into Nbz-Peptides

The resin bound peptide containing the Dbz linker was acylated using 4-nitrophenylchloroformate in DCM (16 equiv., $0.05 \mathrm{M}, 55 \mathrm{~min}$, RT). The resin was washed well with DCM and activated with 0.5 M DIPEA in DMF (195 equiv., $0.5 \mathrm{M}, 20 \mathrm{~min}, \mathrm{RT}$ ). Resin was washed with DMF followed by DCM and dried under $\mathrm{N}_{2}$. The peptide$\mathrm{Nbz}$ was cleaved from the resin using TFA/TIPS/water (95.5:0.25:0.25, 2-3 h). The precipitated peptide-Nbz was redissolved in $50 \% \mathrm{AcN} / 0.05 \% \mathrm{TFA}$ in water and freeze dried.

\section{Cyclization/Ligation}

A 'one pot' buffer for peptide cyclization/ligation was prepared using $200 \mathrm{mM}$ MPAA, $20 \mathrm{mM}$ TCEP and $6 \mathrm{M}$ guanidine in a $200 \mathrm{mM}$ phosphate buffer. The $\mathrm{pH}$ was adjusted to be between $\mathrm{pH}$ 7.0-7.2. Kalata-Nbz (1 mM) and SFTI-1 (2 mM) were incubated in the 'one pot' buffer for $24 \mathrm{~h}$. For the ligation of the two defensin fragments, fragment $1-\mathrm{Nbz}(2 \mathrm{mM})$ and fragment $2(2.5 \mathrm{mM})$ were incubated together in the 'one pot' buffer for $24 \mathrm{~h}$. After $24 \mathrm{~h}$ the 'one pot' buffer containing the cyclized products was desalted through a Sephadex PD 10 column. The column was equilibrated with $20 \mathrm{ml}$ of $30 \% \mathrm{AcN}$ in water. The sample of cyclized peptide was dissolved and applied in $2 \mathrm{ml} 30 \% \mathrm{AcN}$ solution and eluted with $30 \% \mathrm{AcN}$ in water ( $3 \mathrm{ml} \times 3$ fractions). The fractions having the expected mass for the cyclic/ligated peptides were identified by MS and freeze dried.

\section{Oxidative Folding}

Before oxidative folding, the cyclized kalata $\mathrm{B} 1$ was completely reduced using $10 \mathrm{mM}$ DTT in $0.1 \mathrm{M} \mathrm{NH}_{4} \mathrm{HCO}_{3}$ buffer $(\mathrm{pH} 8.5)$ for $1 \mathrm{~h}$, purified by RP-HPLC and freeze dried. Reduced, cyclized kalata B1 was then oxidized in a folding buffer of $0.1 \mathrm{M} \mathrm{NH}_{4} \mathrm{HCO}_{4}(\mathrm{pH} 8.5)$ and isopropanol $(50: 50 \mathrm{v} / \mathrm{v})$ containing $2 \mathrm{mM}$ reduced glutathione and $0.4 \mathrm{mM}$ oxidized glutathione for $24 \mathrm{~h}$. After $24 \mathrm{~h}$ the reaction mixture was quenched with $0.4 \%$ TFA and purified by RPHPLC. SFTI-1 oxidized in the 'one pot' buffer for peptide cyclization/folding.

\section{Results}

Synthesis of the Cyclic Cystine Knotted kalata B1

The synthesis of the cyclotide kalata B1 was initiated on the Tentagel Rink amide resin with a C-terminal Di-Fmoc-3, 4-diaminobenzoic acid (Di-Fmoc-Dbz) linker and an
N-terminal Boc-Cys. Coupling the Di-Fmoc-Dbz linker to the resin and removal of its Fmoc protecting groups were carried out manually (outside the synthesizer) at RT. The choice of the Di-Fmoc-Dbz linker is slightly different from the Fmoc-3,4-diaminobenzoic acid (Fmoc-Dbz) linker that was originally reported (Blanco-Canosa and Dawson 2008). The Fmoc-Dbz linker has only one of the two amino groups protected by Fmoc whereas the linker in the current study has both amino groups at positions 3 and 4 protected. Complete coupling of the Di-Fmoc-Dbz occured at only 2 equiv. relative to the resin in contrast to 8 equiv. of FmocDbz as reported earlier (Blanco-Canosa and Dawson 2008). It appears likely that any potential oligomerization of the $\mathrm{Dbz}$ is avoided during coupling as both amino groups are protected, leading to more efficient coupling.

A complete summary of the synthesis conditions is given in Table 1. The Gly next to Cys (in loop 3) was selected as the initiation point for synthesis (highlighted by the arrow in Fig. 2) to prevent any possibility of epimerization and to facilitate fast reaction. In all there are five other possible synthesis initiation points next to the other Cys residues. In the method introduced by Blanco-Canosa and Dawson (2008) for the production of peptide thioesters, peptide chain extension ideally occurs only at one of the two unprotected amines of the Dbz-linker (either the amine in 3 or 4 position), whereas the other amine gets inactivated following initial acylation due to electronic and steric effects. However, one problem that have been observed for Gly-rich sequences and long, difficult to synthesize, peptides is the accumulation of acylated or branched products arising from the second, free, amine of Dbz (Mahto et al. 2011). To prevent branching, we coupled the first Gly at 1 equiv. relative to the resin as a single coupling (30 min, RT). The remaining portion of the peptide was then elongated in the automated peptide synthesizer by standard Fmoc SPPS with the assistance of microwave heating during deprotection and coupling steps. A crude yield of $63 \%$ was obtained for kalata-Dbz by quantitative cleavage of a portion of the resin, and integration of the UV trace at $215 \mathrm{~nm}$ gave $76 \%$ purity. Yields and purities are summarized in Table 2 and masses of synthetic products are shown in Table 3. Given that this yield was obtained after single couplings of all amino acids (except Arg) in the automated synthesizer using the default cycles from the manufacturer, and without monitoring coupling efficiency, there could be further room for improving the crude yield of the peptide. Expected amount of peptide-Dbz was calculated taking into account the amount of resin cleaved, increase in resin weight following synthesis, peptide molecular weight (deprotected and fully protected) and resin substitution value (see details in Supplementary Information, SI).

As demonstrated in Fig. 3a, one of the isomeric forms of kalata-Dbz appeared as the main product on RP-HPLC analysis with the other isomeric form eluting very close to 
a
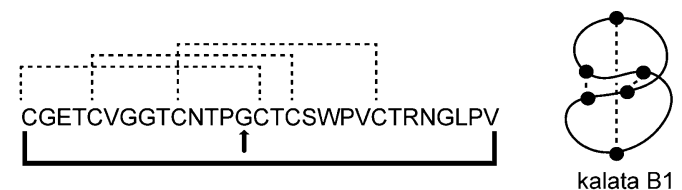

b
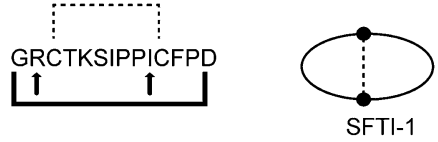

C

C

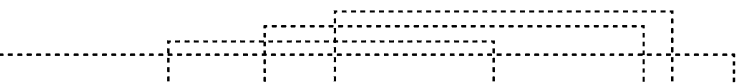

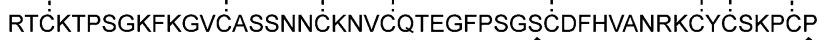

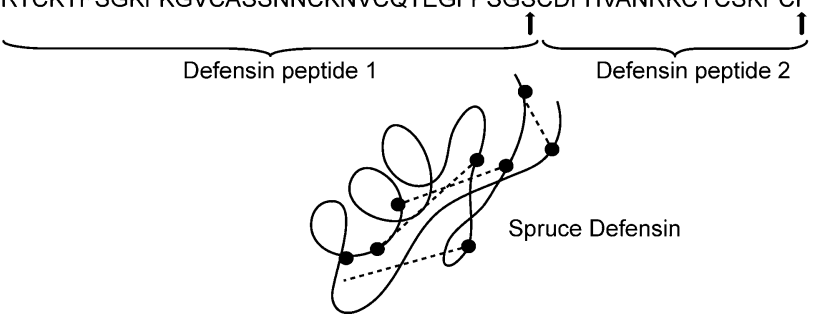

Fig. 2 Sequences and schematic representation of the structures of peptides synthesized in the study. a kalata B1, b SFTI-1 and $\mathbf{c}$ the 50 amino acid long spruce defensin 1 . The synthesis initiation point in each peptide is highlighted by arrow $(s)$. Dashed connecting lines indicated the disulfide bonds and the bold connecting lines indicate the cyclized backbone

Table 2 Yield of kalata B1 and SFTI-1

\begin{tabular}{clllll}
\hline Peptide & $\begin{array}{l}\text { Peptide- } \\
\text { Dbz } \\
\text { recovery } \\
(\%)^{\mathrm{a}}\end{array}$ & $\begin{array}{l}\text { Peptide- } \\
\text { Dbz } \\
\text { purity } \\
(\%)^{\mathrm{b}}\end{array}$ & $\begin{array}{l}\text { Peptide- } \\
\text { Nbz } \\
\text { recovery } \\
(\%)\end{array}$ & $\begin{array}{l}\text { Peptide- } \\
\text { Nbz } \\
\text { purity } \\
(\%)\end{array}$ & $\begin{array}{l}\text { Native } \\
\text { peptide } \\
\text { yield }(\%)\end{array}$ \\
\hline $\begin{array}{c}\text { Kalata } \\
\text { B1 }\end{array}$ & 63 & 76 & 62 & 67 & 16 \\
SFTI-1 & 81 & 79 & 89 & 88 & 50 \\
\hline
\end{tabular}

${ }^{\text {a }}$ Peptide recovery is based on quantitative cleavage of peptide from resin

${ }^{\mathrm{b}}$ Peptide purity is based on HPLC detection trace at $215 \mathrm{~nm}$

Table 3 Expected and Observed peptide masses

\begin{tabular}{ll}
\hline Peptide & $\begin{array}{l}(\mathrm{M}+\mathrm{H})^{+} \text {calculated } \\
(\text { observed })\end{array}$ \\
\hline Kalata-DBZ & $3048.34(3048.76)$ \\
Kalata-NBZ & $3074.33(3075.08)$ \\
Kalata B1 (cyclized and oxidized) & $2891.19(2891.86)$ \\
SFTI-DBZ & $1666.88(1665.94)$ \\
SFTI-NBZ & $1692.88(1691.08)$ \\
SFTI-1 (cyclized and oxidized) & $1513.72(1512.72)$ \\
Defensin peptide 1 & $1970.84(1969.84)$ \\
Defensin peptide 2-DBZ & $3840.01(3839.01)$ \\
Defensin peptide 2-NBZ & $3866.01(3865.10)$ \\
Defensin peptide (ligated) & $5658.71(5657.84)$ \\
\hline
\end{tabular}
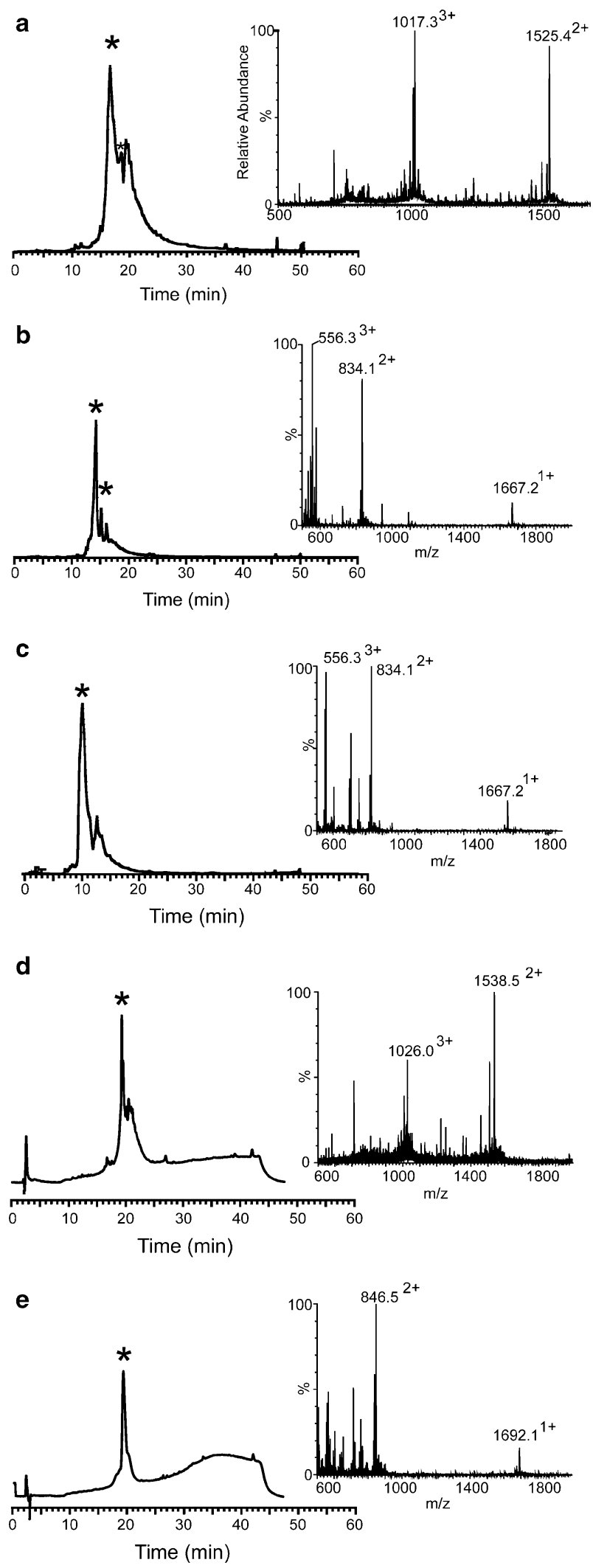

Fig. 3 LC-UV-MS analysis of Dbz and Nbz peptides. a kalata B1-Dbz, b SFTI- $1_{\text {Arg }}-$ Dbz c SFTI- $1_{\text {Ile }}-$ Dbz d kalata-Nbz e SFTI- $1_{\mathrm{Arg}}$ -Nbz. Chromatograms show the UV trace at $215 \mathrm{~nm}$; mass spectra of the main peaks (marked by *) are shown to the right 
the main peak as a secondary peak. In addition, a byproduct with a mass increase of 56.24 Da was observed. That mass increase may stem from a tert-butyl $(\mathrm{tBu})$ protecting group $(56.11 \mathrm{Da})$ or an extra Gly residue $(57.05 \mathrm{Da})$. To rule out that the by-product was not due to the coupling of Gly on the free amino group on Dbz (i.e. from branching), MS-MS was done on the ion with the adduct and of the "native" ion. As shown in SI (Fig. 1), the analysis clearly showed that the unprotected amine on Dbz was not acylated, and we conclude that the extra mass was the result of a tBu-protecting group at a Cys or Thr in the sequence. Although we repeated our cleavage procedure by increasing the thiol scavenger (TFA/TIPS/DODT/water, 92.5.5/2.5/2.5/2.5), the peak with the extra mass of 56.24 was still observed as a minor peak.

Following synthesis, the peptide C-terminus was activated through acylation with $p$-nitrophenylchloroformate. Addition of base resulted in the resin-bound peptide benzimidazolinone (kalata B1-Nbz). After cleavage and deprotection, kalata $\mathrm{B} 1-\mathrm{Nbz}$ was obtained in $62 \%$ yield and the purity was $67 \%$ according to HPLC. No aminoanilide products were observed in the HPLC analysis, indicating that complete conversion of the benzimidazolinone has occurred. The crude peptide-Nbz was then incubated in the 'one pot' buffer for thioesterification and cyclization in situ. After $24 \mathrm{~h}$, cyclized kalata B1 was purified using SEC with $80 \%$ recovery.

In our early attempt to isolate cyclized kalata B1 by HPLC from the 'one pot' buffer, we observed that cyclized kalata B1 coeluted with thiols. Although extraction with diethylether enabled separation of the peptide from thiols, a significant amount of peptide $(\sim 50 \%)$ could not be recovered through RP-HPLC. Cyclized kalata B1 collected by SEC contained oxidized Cys, but analytical RP-HPLC indicated several peaks with retention times earlier than the native kalata $\mathrm{B} 1$, indicative of misfolded kalata B1 (data not shown). Thus, cyclized kalata B1 was completely reduced and refolded in a buffer optimized for correct folding (Daly et al. 2003). Co-injection of $0.1 \mu \mathrm{l}$ each of kalata B1 refolded $(0.2 \mathrm{mg} / \mathrm{ml})$ and native kalata B1 $(0.2 \mathrm{mg} / \mathrm{ml})$ confirmed the native conformation of synthetic kalata B1 (Fig. 4a). From 17.4 mg of peptide-Nbz, $4.2 \mathrm{mg}$ of final pure kalata B1 was obtained. This corresponds to a total yield of $16 \%$, as calculated from the resin substitution value.

\section{Synthesis of the Cyclic SFTI-1}

Coupling the Di-Fmoc-Dbz linker to the resin was carried out as previously described in the synthesis of kalata B1. Two SFTI-1 variants were made; initiated at Arg or at Ile as outlined in Fig. 2. In each case, the synthesis ended with an N-terminal Boc-protected Cys-residue. The coupling of the first amino acid in SFTI-1 variants $\left(\right.$ SFTI- $1_{\text {Arg }}$ and SFTI-1 $1_{\text {Ile }}$ ) gave incomplete coupling when HBTU was used as the coupling agent: despite increasing the amino acid and coupling agent equivalents or increasing the coupling incubation time as (see SFTI-1 syntheses a-d as described
Fig. 4 Analyses and structures of cyclic end products. Chromatograms show the coinjection of synthetic and native peptides on LC-MS; the mass spectra of the peaks, and the structures of a kalata B1 and b SFTI-1

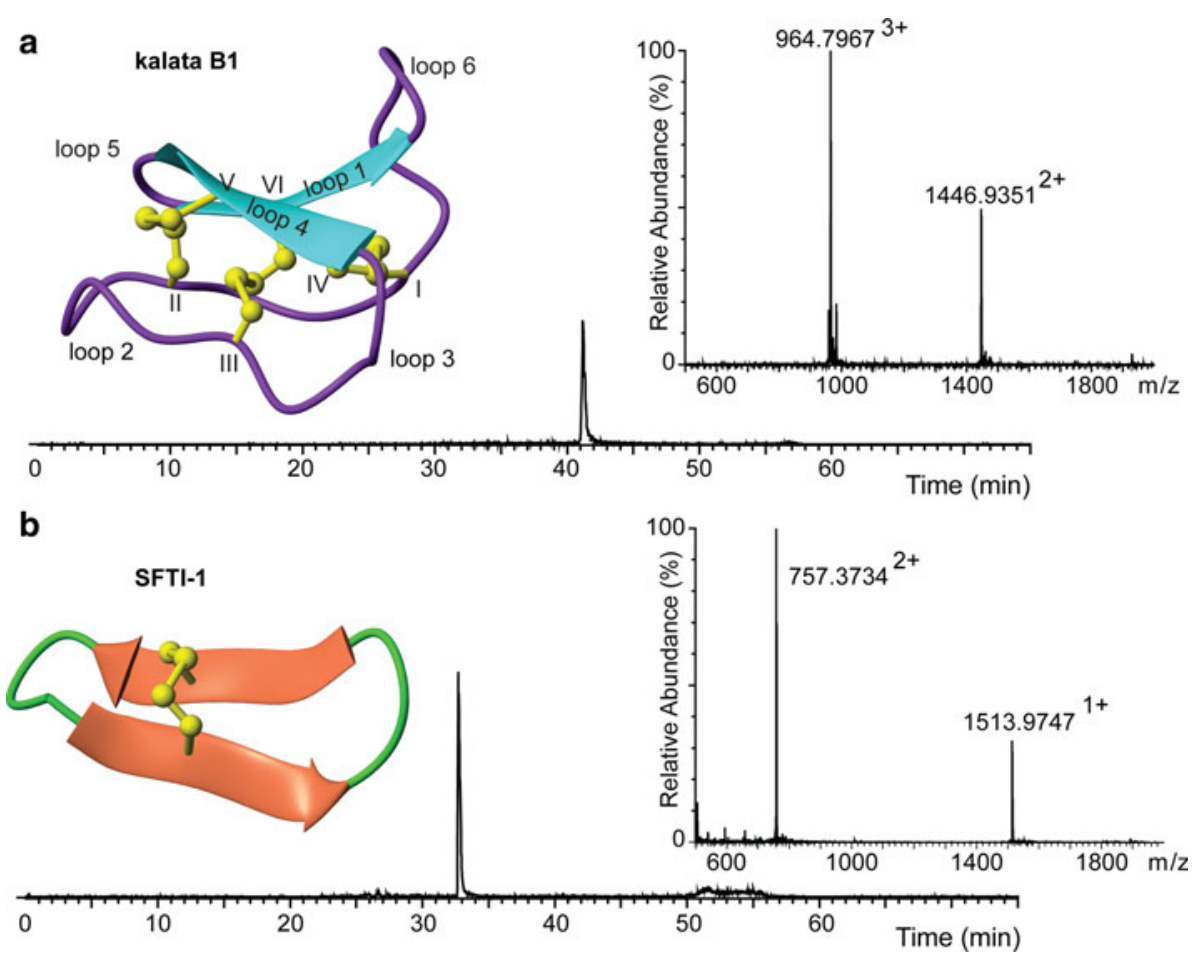


in SI). One challenge during peptide synthesis is $\delta$-lactam formation when coupling Arg (Cezari and Juliano 1996). The formation of $\delta$-lactam occurs when the internal nitrogen of the guanidine attacks the activated ester, irreversibly forming the lactam ring. This reaction is competitive with peptide-bond formation, and greatly reduces the coupling efficiency of Arg. It is possible that lactam formation is favored over the coupling of Arg to Dbz when HBTU is used as a coupling agent. Ile was also difficult to couple to the Dbz linker using HBTU. It is well established that $\beta$-branched amino acids are prone to form $\beta$ sheets, often lead to aggregation during peptide strand elongation resulting in poor coupling efficiency (Garcia-Ramos et al. 2009). Thus, it appears that the structural features of the amino acid that is coupled to the Dbz linker could play an important role in the coupling efficiency. In contrast, the use of HATU as the coupling agent gave complete coupling of the first amino acids (Arg and Ile) to the Dbz linker, at 6 equiv. relative to the resin. The full sequence was then assembled using microwave assisted Fmoc SPPS on the Liberty 1 synthesizer.

One of the most frequently encountered side reactions affecting Asp in Fmoc SPPS is aspartimide formation, resulting from a ring closure between the $\mathrm{N}$ of the $\alpha$-carboxy amide bond and the $\beta$-carboxy side chain of the Asp with the loss of ester protecting group (Tam et al. 1988). The sequence Asp-Gly is prone to aspartimide formation, which in turn may undergo base catalysed epimerization to give $\alpha$ - and $\beta$-piperidide products in the presence of piperidine. SFTI-1 contains the problematic Asp-Gly sequence. In particular, when the synthesis of SFTI-1 is initiated at Arg, the Asp-Gly sequence is encountered early in the synthesis we anticipated that aspartimide formation is likely to occur due to repeated exposure to piperidine during synthesis. Thus, the Asp-Gly sequence was introduced in the form of Fmoc-Asp(OtBu)-(DMB)Gly-OH, with protecting groups on the $\mathrm{N}$ of $\alpha$-carboxy amide and $\beta$-carboxy side chain, to circumvent the problem in the final syntheses. Analysis of crude SFTI-Dbz peptides by RP-HPLC revealed a prominent peak with the corresponding mass for SFTI-Dbz.

Similar to kalata-Dbz synthesis, a by-product with an extra mass of 56.24 Da was also found for SFTI-1-Dbz, as indicated in Fig. 3. However, in the case of SFTI, it is clear from the synthesis in which Asp-Gly was introduced as a dipeptide, that the adduct can not originate from branching at the second, free amine, of Dbz. (In that case, the adduct would have the mass of the dipeptide, not Gly alone). MS-MS analysis confirmed that there was no branching; again, a tBu group is the likely culprit for the by-product. The yield of the crude peptide-Dbz was $81 \%$ for SFTI $-1_{\mathrm{Arg}}$-Dbz and $77 \%$ for SFTI- $1_{\text {Ile }}$-Dbz. HPLC integration peaks gave a purity of 79 and $80 \%$, respectively.
Acylation, activation and cleavage of the acyl urea peptide were carried out for SFTI- $1_{\mathrm{Arg}}$-Dbz. SFTI- $1_{\mathrm{Arg}}$-Nbz was obtained in $89 \%$ yield and the purity was $88 \%$. Yields and purities are summarized in Table 2 and masses of synthetic products are shown in Table 3.

After incubation of the crude $N$-acylurea peptide in the 'one pot' buffer for $24 \mathrm{~h}$, cyclized SFTI-1 was purified by SEC with $80 \%$ recovery. MS analysis demonstrated that cysteines were oxidized. Because SFTI-1 contains only one disulfide bond, it seemed likely that SFTI-1 attained its native conformation in the 'one pot' buffer. LC-MS analysis confirmed that that was the case: as shown in Fig. 4, co-injection of equal amounts of synthetic SFTI-1 and native SFTI-1 co-elutes as a single peak. On a preparative scale, synthetic SFTI-1 collected from SEC was purified by RP-HPLC as a final step. From $18.6 \mathrm{mg}$ of peptide-Nbz, $10 \mathrm{mg}$ of pure SFTI1 was obtained. This corresponds to a total yield of $50 \%$ of the final product (calculated from the resin substitution value).

\section{Synthesis of a Plant Defensin by Ligation of Fragments}

Encouraged by the successful synthesis of kalata B1 and SFTI-1, we then decided to apply the same principles of $\mathrm{N}$-acylurea mediated NCL in the synthesis of a 50-residue long plant defensin, spruce defensin (SPI1) (Sharma and Lonneborg 1996; Elfstrand et al. 2001). The defensin was made in two segments, a 33 residue long $\mathrm{N}$-terminal peptide containing a C-terminal Dbz linker (Fragment 1) and the 17 residue C-terminal peptide (Fragment 2). In Fragment 1, the Di-Fmoc-Dbz group was coupled to a Clear amide resin and the synthesis was initiated at a Ser residue, and a Boc-Arg was introduced as the N-terminal residue. The peptide was elongated by Fmoc SPPS under microwave heating. Fragment 2 was entirely synthesized in the microwave synthesizer using a Pro preloaded resin. During the syntheses, small samples of the resins were cleaved to confirm synthesis accuracy. Fragment 2 (crude yield of $90 \%$ ) was subsequently purified by RP-HPLC.

Fragment $1-\mathrm{Nbz}$ was generated by the now established procedures for acylation, activation and cleavage. The two fragments were then incubated together in the 'one pot' buffer for $24 \mathrm{~h}$ using a slightly higher concentration of fragment $2(2.5 \mathrm{mM}$ for fragment 2 and $2 \mathrm{mM}$ for fragment 1-Nbz). As indicated in Fig. 5, the ligation proceeded efficiently, and the only side product arose from trace hydrolysis. The ligated peptide was then collected by SEC and analysed by LC-MS; the ligated peptide appeared as a broad peak, presumably due to its larger size $(5.6 \mathrm{kDa})$ and unfolded conformation. 


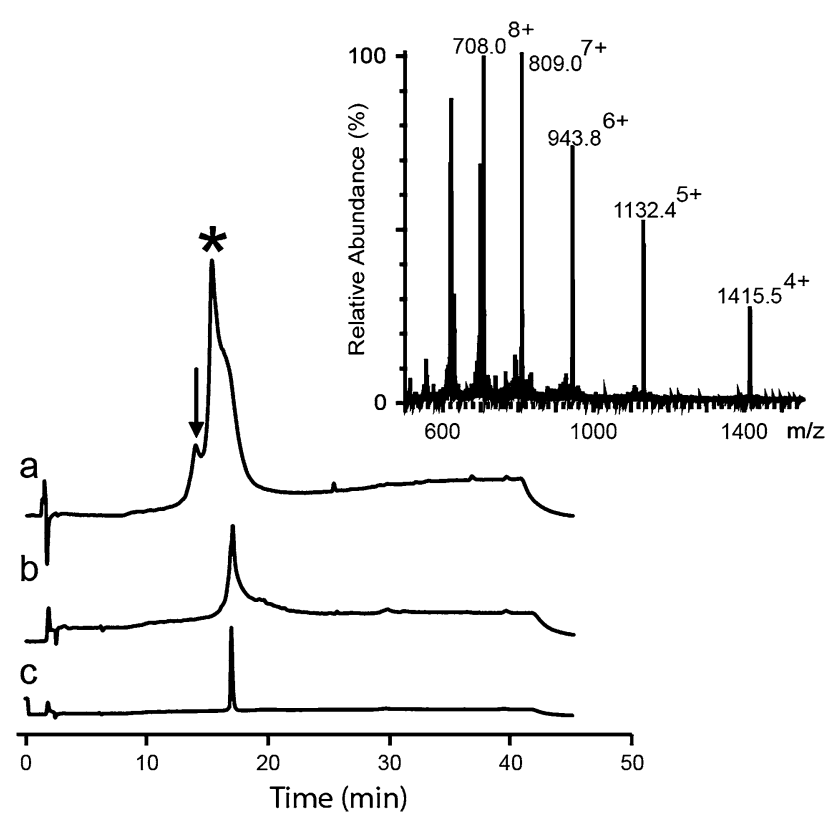

Fig. 5 Analysis of truncated counterpart defensin peptides (fragment 1-Dbz and fragment 2) and the ligated spruce defensin peptide. a Ligated spruce defensin peptide is indicated by * with the corresponding MS trace. Hydrolyzed Nbz peptide is indicated by an arrow. b Defensin peptide 1-Dbz, and $\mathbf{c}$ defensin peptide 2

\section{Discussion}

In the current study we have used $\mathrm{N}$-acylurea mediated native chemical ligation to generate two model cyclic peptides and a 50 residue long, linear peptide. The method relies on the synthesis of a peptide with a $\mathrm{C}$-terminal $\mathrm{Dbz}$ linker and a $\mathrm{N}$-terminal Cys, given the peptide is intended to be head-to-tail cyclized (kalata B1 and SFTI-1). Alternatively, a peptide synthesized with a C-terminal $\mathrm{Dbz}$ linker can be linked to a second peptide containing an $\mathrm{N}$-terminal Cys, to yield one larger molecule (as in the case of the defensin). Following synthesis, the Dbz linker is activated to yield an $\mathrm{N}$-acylurea moiety that acts as poor nucleophile to efficiently form a thioester at the C-terminal. In the presence of the $\mathrm{N}$-terminal Cys, the thioester peptide then participates in NCL to form a native amide bond leading to either peptide cyclization or ligation.

There are several differences in our synthesis protocol from the one originally reported by Blanco-Canosa and Dawson (2008). The type of the Dbz linker used in the current study has both of its amino groups protected by Fmoc groups which is advantageous in terms of improving coupling efficiency as self-dimerization of the linker is prevented. In addition, we demonstrate that the strategy is compatible with microwave irradiation for deprotection and coupling to accelerate the speed of synthesis. Furthermore, we show that Arg, Ile and Ser can be used as starting points for syntheses; but it appears that the structural features of the amino acids play an important role in the coupling efficiency and requires case-specific optimization. Specifically, we found that Arg and Ile require HATU as a coupling agent, whereas Gly should be coupled at low equivalences to prevent possible branching of the second amino group on Dbz. Furthermore, due to the hydrophobicity of the peptides we have synthesized, their co-elution with thiols when separated by RP-HPLC has been problematic. Thus, in place of RP-HPLC, we have successfully used SEC to desalt the cyclized peptides.

SFTI- 1 could be obtained in high total yields compared to kalata B1 (yields are summarized in Table 2). Because SFTI-1 is only 14 residues in length and also has only a single disulfide bond, its synthesis and folding are less complex than kalata B1. Following incubating SFTI-1-Nbz in the 'one pot' buffer, native SFTI- 1 could be easily isolated by SEC and a single step of RP-HPLC. Kalata B1 synthesis is comparatively more laborious and results in lower yields than SFTI-1 because twice as many coupling cycles are needed to assemble the 29-residue peptide. Furthermore, two rounds of HPLC purification were required for kalata $\mathrm{B} 1$, first to isolate the fully reduced peptide and then to isolate the final native peptide following oxidative folding. However, it should be emphasized that no re-couplings (except for Arg) or optimizations were made for the automated peptide synthesis and the efficiency of each amino acid coupling was not monitored by the ninhydrin test. Most likely, there is room for further improvement of the current synthetic yields.

Currently, there are several methods for the chemical synthesis of natural and engineered cyclotides, as outlined in Fig. 6. Boc SPPS based methods were the first to be developed for cyclotide synthesis and is still the dominating method. Boc SPPS is often referred to as the most robust method of cyclotide synthesis, simply because the linear cyclotide precursors can be conveniently generated on resin as crude thioester peptides. However, it should be noted that at least two rounds of purification are required, first to isolate the desired thioester peptides and then the cyclized and natively folded cyclotide, with each purification step often leading to some amount of unrecoverable peptide. The microwave assisted Boc SPPS strategy is reported to give $>60 \%$ yield of crude thioester peptide and $20 \%$ yield of pure kalata B1 from thioester peptide.

The need to develop an Fmoc-based strategy without having to use HF in the final cleavage of peptide from resin and also with the opportunity to conveniently automate, drove the search of alternative denovo cyclotide synthesis methods. Thongyoo et al. successfully synthesized MCoTIII by Fmoc synthesis based on a sulfonamide ('safety catch') linker, by activating the thioester precursors required for NCL following peptide elongation (Thongyoo et al. 2006). However, the resulting thioester peptide was 
Fig. 6 Different cyclotide synthesis strategies. a Boc SPPS strategy, b Fmoc SPPS strategy (based on thioesterification of protected peptide) and $\mathbf{c}$ the Fmoc SPPS strategy used in the current work (based on $N$-acylurea peptide intermediates)
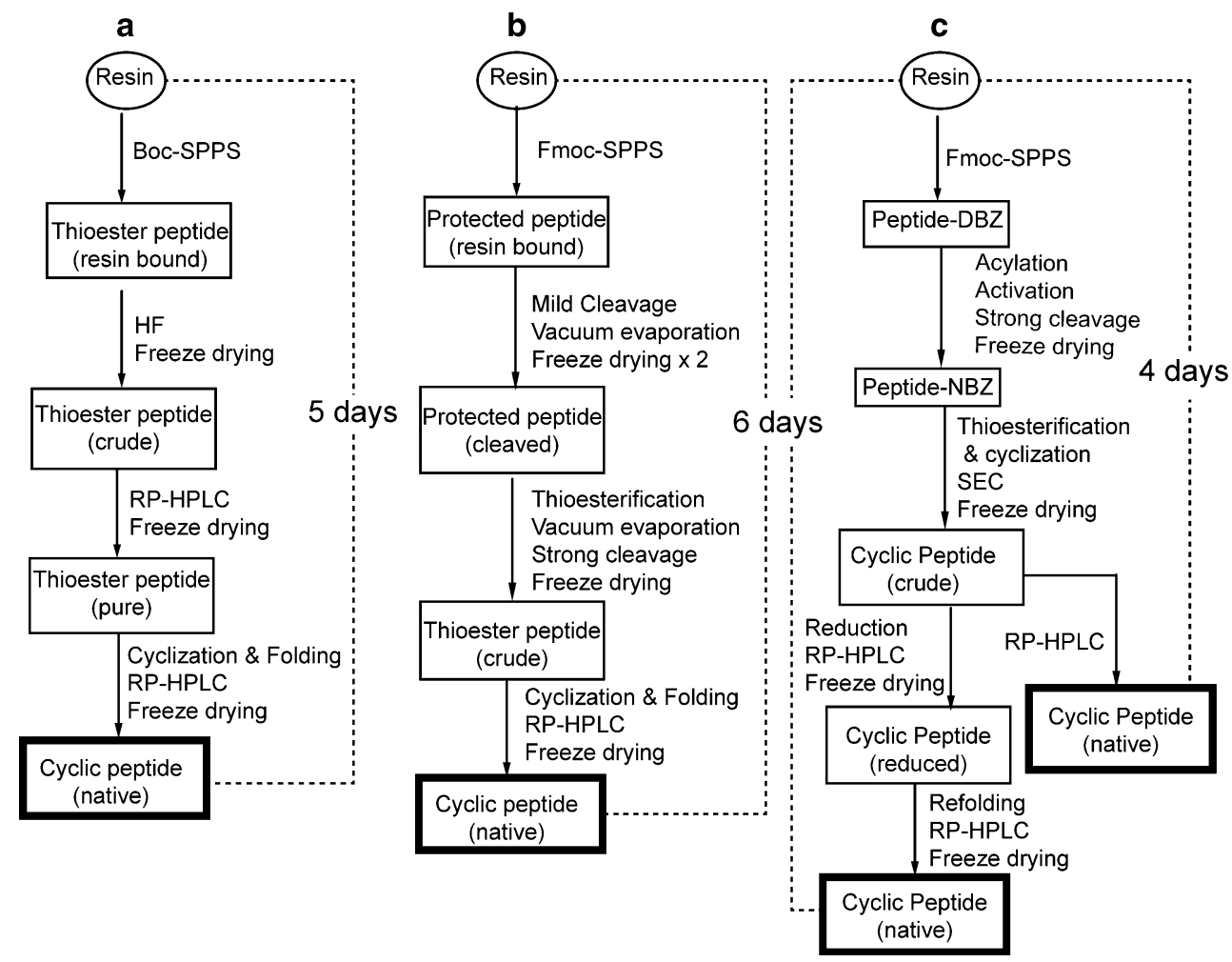

isolated only in $15 \%$ yield and the yield of native peptide is not reported. We have previously described a Fmoc SPPS protocol for cyclotide synthesis in which thioester peptide needed for NCL is generated in solution by reacting a protected peptide with thiols (Fig. 6b) (Leta Aboye et al. 2008; Park et al. 2010). This strategy gives good total yields for cyclotides, $\sim 22 \%$ kalata B1 and $\sim 11 \%$ MCoTI-I yields (yield calculated from the resins). One of the advantages of that strategy is that the crude thioester peptide can be directly converted into a natively folded, cyclized peptide in a 'one pot' buffer without an intermittent HPLC purification step. However, the need to make protected peptide has one drawback: the thioesterification step is extremely sensitive to any residual acid remaining from the mild acid cleavage, thus efficient vacuum evaporation ( $<2$ mbar) of the protected peptide and at least two rounds of lyophilization are necessary to obtain protected peptide free of residual acid.

In comparison, the current protocol does not require a protected peptide to be cleaved off from the resin. The $N$-acylurea peptides can be directly generated and cleaved off from the resin followed by in situ thioesterification/ cyclization in a 'one pot' buffer. Thus, high yield of cyclic/ ligated peptide can be generated with accelerated speed. In case of SFTI-1, correct folding also takes place in the 'one pot' buffer, and the native peptide can be isolated in high yields. In comparison, kalata B1 was completely reduced and refolded to reach the native disulfide connectivity. The extra purification required contributes to the lower total yield of that peptide, but it should be noted that folding conditions have not yet been optimized: with the increasing knowledge of cyclotide oxidative folding (Aboye et al. 2011 ) it is likely that the extra purification step can be omitted in the future.

To date SFTI-1 has been chemically synthesized by different approaches. The most robust approach is via Boc SPPS in which the peptide is synthesized with C-terminal thioester linker and N-terminal Cys to facilitate cyclization by NCL (Daly et al. 2006). In addition, linear SFTI-1 precursors have been synthesized by Fmoc SPPS followed by head-to-tail cyclization to obtain the cyclic backbone with the assistance of coupling agents such as PyBop (Zablotna et al. 2002; Swedberg et al. 2011). In that case, an amino acid side chain protected peptide precursor is usually required to ensure that amide bond formation occurs only between an activated C-terminal carboxylate and an N-terminal Cys. Thus, two cleavage steps are needed: 'mild' cleavage of the protected peptide prior to cyclization and subsequently a 'strong' deprotection. This may influence the yield of final peptide. In comparison, $N$-acyl peptides can be readily generated on resin and cleaved off from the resin by strong cleavage. Peptide can be then efficiently cyclized in a one pot buffer leading to high peptide yields.

The general applicability of the synthesis protocol was exemplified by the synthesis of a 50-residue long plant 
defensin. In principle, we have shown that a large, difficult to synthesize peptide can be ligated via two shorter fragments using the $N$-acylurea approach. Although we currently only have demonstrated the utility of this ligation approach in Cys containing peptides, other potential ligation sites such as Ala or Val broadens the applicability of this approach in the synthesis of peptides that do not contain Cys. For instance, desulfurization allows penicillamine to be converted into Val (Haase et al. 2008) and Cys into Ala (Wan and Danishefsky 2007). Hence, the current approach in combination with desulfurization can potentially be used to ligate peptides that lack Cys, given that they fulfill the requirement of an Ala or $\mathrm{Val}$ at the ligation site.

A user-friendly and time-efficient method of synthesis is a primary requirement to exploit the drug development aspects of cyclic peptides or to dissect their structureactivity relationships. As such the method presented in this study is timely, as many laboratories are becoming more inclined to use Fmoc SPPS rather than Boc SPPS and because of the increasing popularity of microwave assisted for peptide synthesis. In addition, the interest of using cyclic peptides as stable drug scaffolds is growing, and includes studies of naturally occurring cyclic peptides but also to the re-engineering of linear peptides by cyclization of the peptide backbone. In addition to cyclotides and SFTI-1, which both are currently scrutinized as scaffolds for drug discovery, current examples include the development of HIV inhibitors from retrocyclins, synthetic cyclic peptides derived from the primate $\theta$ defensin genes (Penberthy et al. 2011), and the cyclization of the conotoxin Vc1.1, which is now undergoing preclinical development for the treatment of neuropathic pain (Carstens et al. 2011). We anticipate that the protocol described in the current paper may advance the use of cyclic peptides for drug development, but also for a fragment based synthesis approach of larger proteins, exploiting the power of microwave assisted peptide synthesis.

\section{Conclusion}

With the rising interest in cyclization as a tool to improve stability of peptides, the chemical synthesis of proteins, and the increasing use of microwave assisted peptide synthesis, there is a need for the continued development of new methods. The current work expands the applications of the C-terminal $\mathrm{N}$-acylurea approach for NCL reported by (Blanco-Canosa and Dawson 2008). By including highyielding and rapid microwave Fmoc SPPS in the protocol, the door is wide open for the efficient ligation of cyclic peptides or larger proteins by making ends meet.
Acknowledgments SG is a Carl Tryggers Foundation post-doctoral fellow. UG is supported by the Swedish Research Council (20075167; 2011-3403), and the Swedish Foundation for Strategic Research (\#F06-0058). HRE and UG were supported by Swedish Research Links (\#2007-6738).

Open Access This article is distributed under the terms of the Creative Commons Attribution License which permits any use, distribution, and reproduction in any medium, provided the original author(s) and the source are credited.

\section{References}

Aboye TL, Clark RJ, Craik DJ, Göransson U (2008) Ultra-stable peptide scaffolds for protein engineering-synthesis and folding of the circular cystine knotted cyclotide cycloviolacin $\mathrm{O} 2$. ChemBioChem 9:103-113

Aboye TL, Clark RJ, Burman R, Roig MB, Craik DJ, Göransson U (2011) Interlocking disulfides in circular proteins: toward efficient oxidative folding of cyclotides. Antioxid Redox Signal 14:77-86

Blanco-Canosa JB, Dawson PE (2008) An efficient Fmoc-SPPS approach for the generation of thioester peptide precursors for use in native chemical ligation. Angew Chem Int Edit 47:6851-6855

Boy RG, Mier W, Nothelfer EM, Altmann A, Eisenhut M, Kolmar H, Tomaszowski M, Kramer S, Haberkorn U (2010) Sunflower trypsin inhibitor 1 derivatives as molecular scaffolds for the development of novel peptidic radiopharmaceuticals. Mol Imaging Biol 12:377-385

Carstens BB, Clark RJ, Daly NL, Harvey PJ, Kaas Q, Craik DJ (2011) Engineering of conotoxins for the treatment of pain. Curr Pharm Design 17:4242-4253

Cezari MHS, Juliano L (1996) Studies on lactam formation during coupling procedures of $N$-alpha- $N$-omega-protected arginine derivatives. Peptide Res 9:88-91

Chan LY, Gunasekera S, Henriques ST, Worth NF, Le SJ, Clark RJ, Campbell JH, Craik DJ, Daly NL (2011) Engineering proangiogenic peptides using stable, disulfide-rich cyclic scaffolds. Blood 118:6709-6717

Clark RJ, Craik DJ (2010) Native chemical ligation applied to the synthesis and bioengineering of circular peptides and proteins. Biopolymers 94:414-422

Clark RJ, Jensen J, Nevin S, Brid C, Adams D, Craik DJ (2010) The engineering of an orally active conotoxin for the treatment of neuropathic pain. J Pept Sci 16:45

Clippingdale AB, Barrow CJ, Wade JD (2000) Peptide thioester preparation by Fmoc solid phase peptide synthesis for use in native chemical ligation. J Pept Sci 6:225-234

Craik DJ, Daly NL, Bond T, Waine C (1999) Plant cyclotides: a unique family of cyclic and knotted proteins that defines the cyclic cystine knot structural motif. J Mol Biol 294:1327-1336

Daly NL, Clark RJ, Craik DJ (2003) Disulfide folding pathways of cystine knot proteins-tying the knot within the circular backbone of the cyclotides. J Biol Chem 278:6314-6322

Daly NL, Chen YK, Foley FM, Bansal PS, Bharathi R, Clark RJ, Sommerhoff CP, Craik DJ (2006) The absolute structural requirement for a proline in the $\mathrm{P} 3$ '-position of Bowman-Birk protease inhibitors is surmounted in the minimized SFTI-1 scaffold. J Biol Chem 281:23668-23675

Dawson PE, Muir TW, Clarklewis I, Kent SBH (1994) Synthesis of proteins by native chemical ligation. Science 266:776-779 
Elfstrand M, Fossdal CG, Swedjemark G, Clapham D, Olsson O, Sitbon F, Sharma P, Lonneborg A, von Arnold S (2001) Identification of candidate genes for use in molecular breedinga case study with the Norway spruce defensin-like gene, Spi 1. Silvae Genet 50:75-81

Garcia-Ramos Y, Giraud M, Tulla-Puche J, Albericio F (2009) Optimized Fmoc solid-phase synthesis of thymosin alpha 1 by side-chain anchoring onto a PEG resin. Biopolymers 92:565-572

Göransson U, Burman R, Gunasekera S, Strömstedt AA, Rosengren KJ (2012) Circular proteins from plants and fungi. J Biol Chem doi. doi:10.1074/jbc.R111.300129

Gran L, Sletten K, Skjeldal L (2008) Cyclic peptides from Oldenlandia affinis DC. Molecular and biological properties. Chem Biodivers 5:2014-2022

Gunasekera S, Foley FM, Clark RJ, Sando L, Fabri LJ, Craik DJ, Daly NL (2008) Engineering stabilized vascular endothelial growth factor-A antagonists: synthesis, structural characterization, and bioactivity of grafted analogues of cyclotides. J Med Chem 51:7697-7704

Gustafson KR, McKee TC, Bokesch HR (2004) Anti-HIV cyclotides. Curr Protein Pept Sci 5:331-340

Haase C, Rohde H, Seitz O (2008) Native chemical ligation at valine. Angew Chem Int Edit 47:6807-6810

Hackeng TM, Griffin JH, Dawson PE (1999) Protein synthesis by native chemical ligation: expanded scope by using straightforward methodology. P Natl Acad Sci USA 96:10068-10073

Jennings C, West J, Waine C, Craik D, Anderson M (2001) Biosynthesis and insecticidal properties of plant cyclotides: the cyclic knotted proteins from Oldenlandia affinis. Proc Natl Acad Sci USA 98:10614-10619

Kenner GW, Mcdermot JR, Sheppard RC (1971) The safety catch principle in solid phase peptide synthesis. Chem Comm 636-637

Korsinczky MLJ, Schirra HJ, Rosengren KJ, West J, Condie BA, Otvos L, Anderson MA, Craik DJ (2001) Solution structures by ${ }^{1} \mathrm{H}-\mathrm{NMR}$ of the novel cyclic trypsin inhibitor SFTI-1 from sunflower seeds and an acyclic permutant. J Mol Biol 311: 579-591

Lindholm P, Göransson U, Johansson S, Claeson P, Gullbo J, Larsson R, Bohlin L, Backlund A (2002) Cyclotides: a novel type of cytotoxic agents. Mol Cancer Ther 1:365-369

Long YQ, Lee SL, Lin CY, Enyedy IJ, Wang SM, Li P, Dickson RB, Roller PP (2001) Synthesis and evaluation of the sunflower derived trypsin inhibitor as a potent inhibitor of the type II transmembrane serine protease, matriptase. Bioorg Med Chem Lett 11:2515-2519

Lovelace ES, Gunasekera S, Alvarmo C, Clark RJ, Nevin ST, Grishin AA, Adams DJ, Craik DJ, Daly NL (2011) Stabilization of alpha-conotoxin AuIB: influences of disulfide connectivity and backbone cyclization. Antioxid Redox Signal 14:87-95

Luckett S, Garcia RS, Barker JJ, Konarev AV, Shewry PR, Clarke AR, Brady RL (1999) High-resolution structure of a potent, cyclic proteinase inhibitor from sunflower seeds. J Mol Biol 290:525-533
Mahto SK, Howard CJ, Shimko JC, Ottesen JJ (2011) A reversible protection strategy to improve Fmoc-SPPS of peptide thioesters by the $N$-Acylurea approach. ChemBioChem 12:2488-2494

Mende F, Seitz O (2011) 9-Fluorenylmethoxycarbonyl-based solidphase synthesis of peptide alpha-thioesters. Angew Chem Int Edit 50:1232-1240

Park S, Gunasekera S, Aboye TL, Göransson U (2010) An efficient approach for the total synthesis of cyclotides by microwave assisted Fmoc-SPPS. Int J Pept Res Ther 16:167-176

Penberthy WT, Chari S, Cole AL, Cole AM (2011) Retrocyclins and their activity against HIV-1. Cell Mol Life Sci 68:2231-2242

Pränting M, Lööv C, Burman R, Göransson U, Andersson DI (2010) The cyclotide cycloviolacin $\mathrm{O} 2$ from Viola odorata has potent bactericidal activity against Gram-negative bacteria. J Antimicrob Chemother 65:1964-1971

Sharma P, Lonneborg A (1996) Isolation and characterization of a cDNA encoding a plant defensin-like protein from roots of Norway spruce. Plant Mol Biol 31:707-712

Svangård E, Göransson U, Hocaoglu Z, Gullbo J, Larsson R, Claeson P, Bohlin L (2004) Cytotoxic cyclotides from Viola tricolor. J Nat Prod 67:144-147

Swedberg JE, de Veer SJ, Sit KC, Reboul CF, Buckle AM, Harris JM (2011) Mastering the canonical loop of serine protease inhibitors: enhancing potency by optimising the internal hydrogen bond network. Plos One 6(4):19302

Tam JP, Riemen MW, Merrifield RB (1988) Mechanisms of aspartimide formation: the effects of protecting groups, acid, base, temperature and time. Pept Res 1:6-18

Thongyoo P, Tate EW, Leatherbarrow RJ (2006) Total synthesis of the macrocyclic cysteine knot microprotein MCoTI-II. Chem Commun 2848-2850

Thongyoo P, Roque-Rosell N, Leatherbarrow RJ, Tate EW (2008) Chemical and biomimetic total syntheses of natural and engineered MCoTI cyclotides. Org Biomol Chem 6:1462-1470

Thongyoo P, Bonomelli C, Leatherbarrow RJ, Tate EW (2009) Potent inhibitors of beta-Tryptase and human leukocyte elastase based on the MCoTI-II scaffold. J Med Chem 52:6197-6200

Wan Q, Danishefsky SJ (2007) Free-radical-based, specific desulfurization of cysteine: a powerful advance in the synthesis of polypeptides and glycopolypeptides. Angew Chem Int Edit 46: 9248-9252

Wang CKL, Kaas Q, Chiche L, Craik DJ (2008) CyBase: a database of cyclic protein sequences and structures, with applications in protein discovery and engineering. Nucleic Acids Res 36: D206-D210

Zablotna E, Kazmierezak K, Jaskiewicz A, Stawikowski M, Kupryszewski G, Rolka K (2002) Chemical synthesis and kinetic study of the smallest naturally occurring trypsin inhibitor SFTI-1 isolated from sunflower seeds and its analogues. Biochem Biophys Res Commun 292:855-859 